\title{
Changes in Intracellular pH Accompanying Chemoreception in the Plasmodia of Physarum polycephalum
}

\author{
By TATSUMI HIROSE, * TETSUO UEDA AND YONOSUKE KOBATAKE \\ Faculty of Pharmaceutical Sciences, Hokkaido University, Sapporo, Japan
}

(Received 5 January 1982; revised 1 March 1982)

\begin{abstract}
A new method for measuring intracellular $\mathrm{pH}$, employing the intrinsic fluorescent pigments of the plasmodia of the myxomycete Physarum polycephalum, was used to study the role of $\mathrm{pH}$ in chemotactic transduction in the plasmodia. The cell became acidified following stimulation with the attractants alanine, glucose, galactose and maltose when their concentrations exceeded the respective thresholds of chemoreception and taxis. The degree of cell acidification paralleled the relaxing tendency in tension generation. A non-metabolizable attractant, 2-deoxyglucose, also acidified the cell. However, the repellent salts $\mathrm{NaCl}, \mathrm{KCl}$ and $\mathrm{CaCl}_{2}$ did not change the intracellular $\mathrm{pH}$. Our results suggest that the effects of attractants are mediated by intracellular $\mathrm{pH}$, while the effects of repellents are transduced by ATP as reported previously.
\end{abstract}

\section{INTRODUCTION}

Plasmodia of the myxomycete Physarum polycephalum react to certain chemicals by chemotaxis (Carlile, 1970; Knowles \& Carlile, 1978; Chet et al., 1977; Kincaid \& Mansour, 1978, 1979; Ueda et al., 1975; Ueda \& Kobatake, 1977a, b; Ataka et al., 1978). Studies on the primary process occurring at the receptive membrane have revealed a conformational change in the membrane, as indicated by changes in membrane fluidity (Ueda \& Kobatake, 1979), zeta potential (Hato et al., 1976a; Ueda \& Kobatake, 1977a), adhesiveness (Ishida et al., 1977) and chemical reactivity (Ishida et al., 1978).

Negative and positive taxes in the plasmodia correlate with contraction and relaxation, respectively (Ueda et al., 1976; Hato et al., 1976 b). Thus the problem of chemotactic transduction is simplified to that of finding modulators of contractile activity in the plasmodia. Recently we have shown that intracellular ATP can be such a mediator for repellent salts, but not for attractants (Hirose et al., 1980).

In the present paper we show that attractant information is transmitted to the motile system through changes in the intracellular $\mathrm{pH}$. The results were obtained using a new method for measuring the intracellular $\mathrm{pH}$, which utilizes the intrinsic fluoresence of pigments in the plasmodia.

\section{METHODS}

Plasmodia. The true slime mould Physarum polycephalum was cultured by the method of Camp (1936). Before use, the plasmodia were allowed to differentiate into tips and strands by migrating on $0.9 \%$ water agar overnight without feeding.

Preparation of pigments from plasmodia. Plasmodial pigments were extracted by dipping plasmodia in five times their weight of hot water $\left(95^{\circ} \mathrm{C}\right)$ for $10 \mathrm{~min}$, and the residues were removed by ultracentrifugation $(50000 \mathrm{~g}$, $30 \mathrm{~min}$ ). The pigments were kept in a measuring solution containing $30 \mathrm{~mm}-\mathrm{KCl}, 3 \mathrm{~mm}-\mathrm{MgCl}_{2}, 10 \mathrm{~mm}-\mathrm{Ca} / \mathrm{EGTA}$ buffer and $10 \mathrm{~mm}-\mathrm{MES}$ buffer. The free $\mathrm{Ca}^{2+}$ concentration and $\mathrm{pH}$ of the test solution were varied between $10^{-8}$ and $10^{-6} \mathrm{M}$ and $6 \cdot 8-7 \cdot 6$, respectively. Other chemicals were added to this solution.

Measurements of fluorescence in vitro and in vivo. Fluorescence spectra of the intrinsic pigment and their second derivatives were measured by a fluorescence spectrophotometer (Hitachi, Model MPF-2A and Shimazu, unit DES-2). Fluorescence spectra of the pigments were measured at the emission peak of $480 \mathrm{~nm}$ by scanning the excitation spectrum from 250 to $360 \mathrm{~nm}$. Measurements of in vivo fluorescence of the plasmodia were performed as 

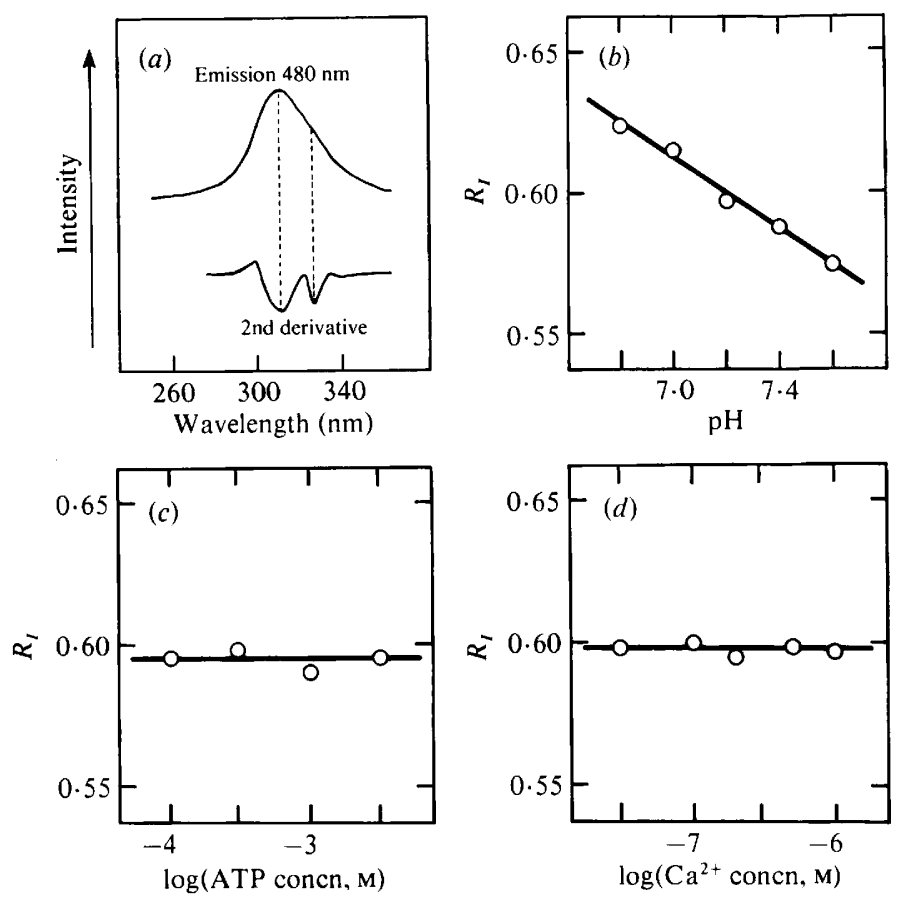

Fig. 1. Fluorescence properties of intrinsic pigments extracted from the plasmodia of Physarum polycephalum. (a) Excitation and the second-derivative spectra monitored at the emission peak of $480 \mathrm{~nm}$. The concentration of pigments was $10 \%$ of that in the intact plasmodia. $(b),(c),(d)$ Fluorescence ratio $R_{l}$ as a function of $\mathrm{pH}$, and ATP and $\mathrm{Ca}^{2+}$ concentrations, respectively. $R_{l}$ is defined as the ratio of fluorescence intensity excited at $325 \mathrm{~nm}$ to that excited at $310 \mathrm{~nm}$.

previously described (Ueda \& Kobatake, 1979) with the minor alteration that quartz plates were used throughout. All experiments were done at room temperature $\left(22^{\circ} \mathrm{C}\right)$ and repeated four or five times for each experimental condition.

\section{RESULTS}

Intrinsic pigments of the plasmodia as $\mathrm{pH}$ indicators

The excitation spectrum of the fluorescent pigments extracted from the plasmodia is shown in Fig. 1(a). The second derivative spectrum indicates that there are two components, at 310 and $325 \mathrm{~nm}$. Thus, the fluorescence intensity at $480 \mathrm{~nm}$ excited by $325 \mathrm{~nm}$ light, relative to that excited by $310 \mathrm{~nm}$ light, $R_{I}=I_{325} / I_{310}$, was measured as a function of the $\mathrm{pH}$ and of the ATP and $\mathrm{Ca}^{2+}$ concentrations. The value of $R_{I}$ decrease linearly with increasing $\mathrm{pH}$ (Fig. $1 b$ ) according to the equation:

$$
R_{I}-0.612=-0.062(\mathrm{pH}-7 \cdot 0)
$$

However, $R_{I}$ was not affected by ATP and $\mathrm{Ca}^{2+}$ in their physiological concentration ranges (Fig. $1 c, d$ ), and was also independent of the amount of the pigments. Therefore, we concluded that the plasmodial pigment is a useful $\mathrm{pH}$ indicator for measuring cytoplasmic $\mathrm{pH}$ in an intact plasmodium.

\section{Changes in intracellular $p H$ induced by chemical stimulation}

Time courses of the fluorescence ratio $R_{I}$ in the intact plasmodia before and after chemical stimulation are shown in Fig. 2. The variation of $R_{I}$ had a period of 2-3 min, which is the same 


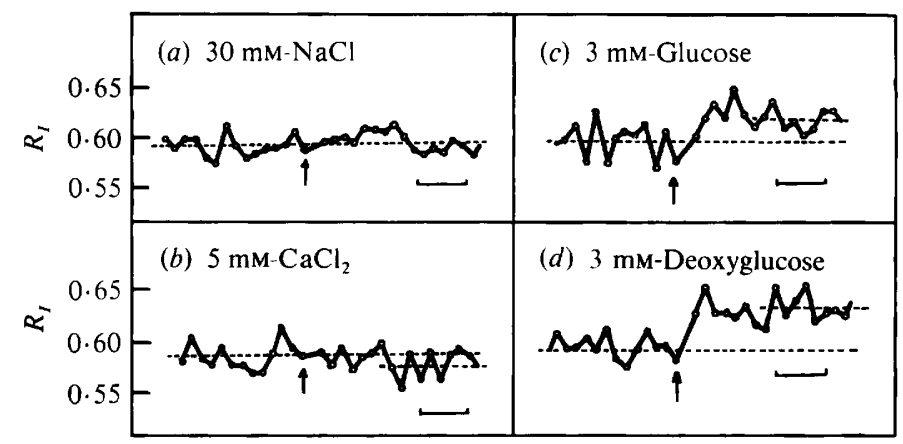

Fig. 2. Time course of changes in intracellular $\mathrm{pH}$ of the plasmodia in response to chemical stimuli. Addition of chemicals is indicated by the arrows. The bars represent $5 \mathrm{~min}$ in each case. The distance between the pairs of broken lines in $(b),(c)$ and $(d)$ represents $\overline{\Delta R}_{l}$.

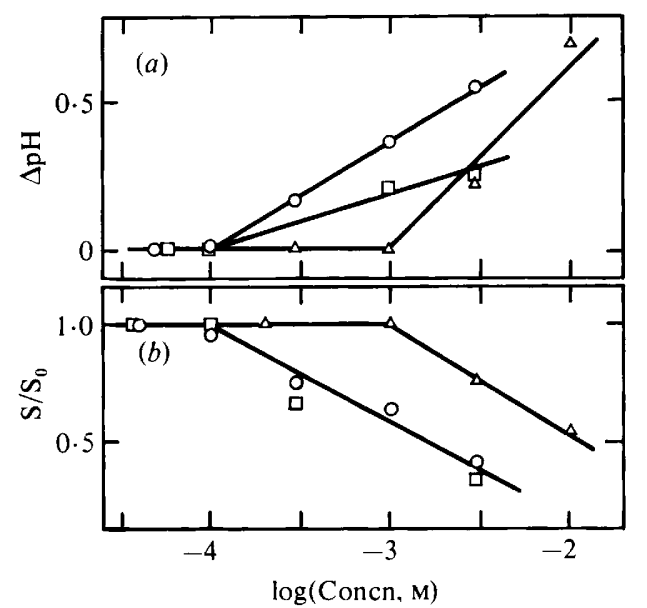

Fig. 3. Dependence of the changes in intracellular $\mathrm{pH}(a)$ and tension generation $(b)$ on the concentration of the attractant sugars glucose $(\bigcirc)$, galactose $(\square)$ and maltose $(\triangle)$. (b) is taken from Ueda et al. (1976); the value of $S$ is defined as an integral of isometric tension with respect to time during a period of oscillation, and $S / S_{0}$ is a ratio of $S$ before and after the addition of chemicals.

Table 1. Comparison of changes in intracellular $p H$ and ATP concentration induced by chemical stimulation

The concentrations of the stimulants indicated in the table are 10-30 times higher than the thresholds for the respective chemicals. The changes in $\mathrm{pH}$ were calculated from the observed $R_{I}$ using equation (1); negative values indicate acidification. The data for ATP concentrations are taken from Hirose $e t a l$. (1980). Numbers in parentheses represent S.D.

\begin{tabular}{llccc} 
Class & \multicolumn{1}{c}{ Chemical } & $\begin{array}{c}\text { Concn } \\
(\mathrm{mM})\end{array}$ & $\mathrm{pH}$ change & $\begin{array}{c}\text { ATP concn } \\
(\% \text { of control) }\end{array}$ \\
Attractants & Alanine & 3 & $-0 \cdot 42( \pm 0.08)$ & $113( \pm 16)$ \\
& 2-Deoxyglucose & 3 & $-0 \cdot 74( \pm 0 \cdot 16)$ & $90( \pm 5)$ \\
& Glucose & 3 & $-0 \cdot 57( \pm 0.08)$ & $97( \pm 8)$ \\
& Galactose & 3 & $-0 \cdot 37( \pm 0.06)$ & \\
Repellents & Maltose & 10 & $-0 \cdot 72( \pm 0 \cdot 14)$ & $109( \pm 4)$ \\
& $\mathrm{NaCl}$ & 30 & $0 \cdot 08( \pm 0.03)$ & $132( \pm 10)$ \\
& $\mathrm{KCl}$ & 30 & $0 \cdot 14( \pm 0.03)$ & $154( \pm 16)$ \\
& $\mathrm{CaCl}$ & 5 & $0 \cdot 15( \pm 0.05)$ & $151( \pm 10)$
\end{tabular}

as the contraction rhythm of the plasmodia. This suggests that intracellular $\mathrm{pH}$ oscillates with the contraction rhythm. This is consistent with the report of Yoshimoto et al. (1981), that the contraction rhythm parallels the oscillation in $\mathrm{pH}$ of the surrounding medium as monitored with 
an $\mathrm{H}^{+}$-sensitive $\mathrm{Sb}$ electrode. Stimulation with attractant sugars such as glucose, galactose, maltose, and also 2-deoxyglucose, increased the $R_{I}$ value, on average (i.e. the cell was acidified by reception of attractant sugars) whereas the repellent salts $\mathrm{NaCl}$ and $\mathrm{CaCl}_{2}$ caused no appreciable variation of $R_{l}$.

This acidification of the cell induced by attractants cannot be attributed solely to possible enhanced glycolysis inside the cell, because 2-deoxyglucose cannot be metabolized in this organism (Knowles \& Carlile, 1978).

The averaged changes in intracellular $\mathrm{pH}$ in response to different sugar concentrations are shown in Fig. 3(a). The intracellular pH was calculated from the averaged change in the relative fluorescence $\overline{\Delta R}_{I}$, using equation (1). The acidification of the cell did not occur until the stimulus chemicals reached their respective thresholds, but thereafter increased with increasing sugar concentration. The results in Fig. $3(b)$ show that the sugars caused a parallel decrease in tension of the plasmodia (Ueda et al., 1976). The thresholds for cell acidification, tension generation and chemoreception were similar.

The changes in intracellular $\mathrm{pH}$ induced by chemical stimulation are summarized in Table 1 . All the attractants examined, namely alanine, glucose, 2-deoxyglucose, galactose and maltose, acidified the cell, whereas the repellent salts $\mathrm{NaCl}, \mathrm{KCl}$ and $\mathrm{CaCl}_{2}$ did not change the intracellular $\mathrm{pH}$.

These results indicate that the acidification of the cell is triggered by attractant chemoreception and acts to relax the tension in the plasmodia.

\section{DISCUSSION}

All the attractants examined, whether amino acid, or metabolizable or non-metabolizable carbohydrate, acidified the cell, whereas the repellent salts did not change the intracellular $\mathrm{pH}$ (Table 1). On the other hand, the repellent salts increase the ATP concentration, leading to plasmodial contraction, whilst the attractants do not affect the ATP level (Hirose et al., 1980). Thus, attractant and repellent salts affect the motile system by different pathways, involving $\mathrm{pH}$ and ATP, respectively.

Evidence that the intracellular $\mathrm{pH}$ can influence the actomyosin system is accumulating: $\mathrm{pH}$ changes produce contraction in Triton-extracted muscle (Taylor, 1976), solation and contraction of gel in amoebae (Hellewell \& Taylor, 1979), actin polymerization in echinoderm sperm (Tilney et al., 1978), and elongation of actin-filled microvilli in sea urchin eggs (Johnson et al., 1976; Shen \& Steinhardt, 1978; Begg \& Rebhum, 1979). All these results indicate that an increase in $\mathrm{pH}$ causes contraction and actin polymerization. The present results, together with those of Yoshimoto et al. (1981), are compatible with these effects of $\mathrm{pH}$ on the actomyosin system.

Some, if not all, of the intrinsic fluorescent pigments have been found as cytoplasmic particles (Daniel, 1966), hence it is plausible that the present method of intracellular pH measurement may reflect values of $\mathrm{pH}$ in the cytoplasm. In fact, a large change in the $\mathrm{pH}$ of the surrounding medium, which might be expected to alter the $\mathrm{pH}$ of the cytoplasm, induced a corresponding change in intracellular $\mathrm{pH}$ as measured by the present method.

This work was partially supported by a Grant in Aid for Scientific Research from the Ministry of Education, Science and Culture, Japan. Thanks are due to Miss Keiko Ohno for performing part of the experiments.

\section{REFERENCES}

Ataka, M., Tsuchil, A., Ueda, T., Kurihara, K. \& Kobatake, Y. (1978). Comparative studies on the reception of bitter stimuli in the frog, Tetrahymena, slime mold and Nitella. Comparative Biochemistry and Physiology 61A, 109-115.

BeGG, D. A. \& Rebhum, L. I. (1979). pH regulates the polymerization of actin in the sea urchin egg cortex. Journal of Cell Biology 83, 241-248.

Camp, W. G. (1936). A method of cultivating myxomycete plasmodia. Bulletin of the Torrey Botanical Club 63, 205-210.
Carlile, M. J. (1970). Nutrition and chemotaxis in the myxomycete Physarum polycephalum: the effect of carbohydrates on the plasmodium. Journal of General Microbiology 63, 221-226.

Chet, I., Naveh, A. \& Henis, Y. (1977). Chemotaxis of Physarum polycephalum towards carbohydrates, amino acids and nucleotides. Journal of General Microbiology 102, 145-148.

DANIEL, J. W. (1966). Light-induced synchronous sporulation of a myxomycete - the relation of initial metabolic changes to the establishment of a new cell 
state. In Cell Synchrony, pp. 117-152. Edited by I. L. Cameron \& G. M. Padilla. New York \& London: Academic Press.

Hato, M., Ueda, T., Kurihara, K. \& Kobatake, Y. $(1976 a)$. Changes in zeta potential and membrane potential of slime mold Physarum polycephalum in response to chemical stimuli. Biochimica et biophysica acta 426, 73-80.

Hato, M., Ueda, T., Kurihara, K. \& Kobatake, Y. $(1976 b)$. Phototaxis in the true slime mold Physarum polycephalum. Cell Structure and Function 1, 155-164.

Hellewell, S. B. \& TAYLoR, D. L. (1979). The contractile basis of ameboid movement VI. The solation-contraction coupling hypothesis. Journal of Cell Biology 83, 633-648.

Hirose, T., Ueda, T. \& Kobatake, Y. (1980). Changes in ATP concentration triggered by chemoreception in the plasmodia of the myxomycete Physarum polycephalum. Journal of General Microbiology 121, 175180.

Ishida, N., Kurihara, K. \& Kobatake, Y. (1977). Changes in adhesive properties of the slime mold Physarum polycephalum accompanied with chemoreception. Cytobiologie, 15, 269-274.

IShida, N., Kurihara, K. \& Kobatake, Y. (1978). Dynamic conformational changes of surface membrane of the true slime mold in response to chemoreception revealed by reactivity with chemical agents. Comparative Biochemistry and Physiology 60 , 241-246.

Johnson, J. J., Epel, D. \& PaUl, M. (1976). Intracellular $\mathrm{pH}$ and activation of sea urchin eggs after fertilization. Nature, London 262, 661-664.

KincaID, R. L. \& Mansour, T. E. (1978). Chemotaxis toward carbohydrates and aminoacids in Physarum polycephalum. Experimental Cell Research 116, 377385.

Kincaid, R. L. \& Mansour, T. E. (1979). Cyclic 3',5'AMP phosphodiesterase in Physarum polycephalum. I. Chemotaxis toward inhibitors and cyclic nucleotides. Biochimica et biophysica acta 588, 332-341.

Knowles, D. J. C. \& Carlile, M. J. (1978). The chemotactic response of plasmodia of the myxomycete Physarum polycephalum to sugars and related compounds. Journal of General Microbiology 108, 17-25.
Shen, S. S. \& Steinhardt, R. A. (1978). Direct measurement of intracellular $\mathrm{pH}$ during metabolic depression of the sea urchin egg. Nature, London 272 , 253-254.

TAYLOR, D. L. (1976). Quantitative studies on the polarization optical properties of striated muscle. Journal of Cell Biology 68, 497-511.

Tilney, L. G., Kiehart, D. P., Sardet, C. \& Tilney, M. (1978). Polymerization of actin. IV. Role of $\mathrm{Ca}^{++}$ and $\mathrm{H}^{+}$in the assembly of actin and in membrane fusion in the acrosomal reaction of echinoderm sperm. Journal of Cell Biology 77, 536-550.

UEDA, T. \& KoBATAKE, Y. (1977a). Hydrophobicity of biosurfaces as shown by chemoreceptive thresholds in Tetrahymena, Physarum and Nitella. Journal of Membrane Biology 34, 351-368.

Ueda, T. \& Kobatake, Y. (1977b). Changes in membrane potential, zeta potential and chemotaxis of Physarum polycephalum in response to $\mathrm{n}$-alcohols, $\mathrm{n}$ aldehydes and n-fatty acids. Cytobiologie 16, 16-26.

UEDa, T. \& Kobatake, Y. (1979). Spectral analysis of fluorescence of 8-anilino-1-naphthalenesulfonate in chemoreception with a white plasmodium of Physarum polycephalum: evidence for conformational change in the chemoreceptive membrane. Biochimica et biophysica acta 557, 199-207.

Ueda, T., Terayama, K. Kurihara, K. \& Kobatake, Y. (1975). Threshold phenomena in chemoreception and taxis in the slime mould Physarum polycephalum. Journal of General Physiology 65, 223-234.

Ueda, T., Muratsugu, M., Kurihara, K. \& KobaTAKE, Y. (1976). Chemotaxis in Physarum polycephalum: effects of chemicals on isometric tension of the plasmodial strand in relation to chemotactic movement. Experimental Cell Research 100, 337-344.

Yoshimoto, Y., Nakamura, S. \& KamiYa, N. (1981). Changes in intracellular $\mathrm{Ca}^{2+}$ and ATP concentrations and intracellular $\mathrm{pH}$ of Physarum plasmodium in relation to its contraction-relaxation cycle. In Proceedings of the VIIth Conference of National Institute for Basic Biology on Mechanism of Cell Movement III, Okazaki, Japan, vol. 7, pp. 45-47. Edited by N. Kamiyia \& H. Ishikawa. 